\title{
EPILEPSIA E EDUCAÇÃO PÚBLICA
}

\author{
D. SIMONATTO * - M. D. DIAS*- T. H. B. PINTO**- M. ALBUQUERQUE***
}

\begin{abstract}
RESUMO - Foi elaborado questionário para obter informações sobre as atitudes pessoais e o conhecimento geral sobre as epilepsias. Foram submetidos a esse questionário professores de primeiro e segundo graus de escolas particulares e públicas, bem como prefessores universitários de áreas médica e não médica, num total de 97 pessoas, restringindo-se à região da Grande São Paulo. Não foram observadas diferenças nos resultados obtidos dos professores de escolas púbiicas, quando comparados aos de escolas particulares. Taxa alta de desinformação foi encontrada nas questões réferentes às atitudes diante de pessoa que esteja apresentando convulsão e, também, quanto ao conceito e à etiologia das epilepsias, inclusive entre professores de área médica. Concluímos que muitos professores (inclusive os de área médica) não: têm conhecimentos suficientes a respeito das epilepsias. evidente a necessidade de programa nacional direcionado não só aos protessores mas, também, à população em geral, visando a levar a atitude mais positiva com relaçáo aos epilépticosı e a melhorar sua qualidade de vida e seu tratamento.
\end{abstract}

PALAVRAS-CHAVE: epilepsia, restrições ao paciente, educação pública.

\section{Epilepsy and public education}

SUMMARY - The social problems experienced by persons with epilepsy become increasingly apparent to those who work closely with group assocations. The objective of our study was to obtain information on personal attitudes and knowledge about epilepsies. Primary and highschool teachers and professors (medical and non-medical areas) were submitted to a questionnaire which was designed to obtain this information. We concluded that most professors (including those of medical areas) do not know enough about epilepsies. We believe that problems which are perceived by epileptics regarding social aspects may be softened through improved education of the community in general. Continued education of medical practioners, professors, teachers, patients and their families leads to a positive attitude towards epilepsies, which are essential and may help to improve life quality and the patient's medical treatment.

KEY WORDS: epilepsy, patient restrictions, public education.

As pessoas com epilepsia estão sujeitas a atitudes de rejeição social desde a infância e, muitas vezes, tais atitudes se iniciam no próprio grupamento familiar, com restrições a frequência ao ambiente escolar e a participação em atividades coletivas próprias da idade 2,11. Niais tarde, a sociedade traz problemas no que tange ao trabalho, pelas suposições errôneas de que ela é limitada em sua inteligência, pouco capaz para o trabalho e mais sujeita a acidentes $6,8,10$. Os problemas sociais vivenciados pelos epilépticos tornaram-se importante realidade que não deve mais ser ignorada por profissionais que trabalhem direta ou indiretamente com a saúde e o bem estar desses pacientes. Esses problemas são bastante evidentes para aqueles que trabalham em grupos ou associações. Os principais problemas sociais são geralmente decorrentes de preconceitos, não só em ambientes familiares e escolares 2,11 , como, também, no que se refere à obtenção

* Médica pela Faculdade de Medicina da Universidade de Mogi das Cruzes (FMUMC); **Auxiliar de Ensino da Discipina de Neurologia da FMUMC; ***Professora Adjunto da Disciplina de Neurologia da FMUMC. Apoio CAPES.

Dra. Marly de Albuquerque - Rua Carmela Dutra 367 - 08780 Mogi das Crures SP - Brasil. 
e manutenção de empregos 4,9. Acreditamos que esses preconceitos são decorrentes da desinformação e da falta de maior esclarecimento de profissionais, familiares, empregadores, população em geral e, até mesmo, do próprio paciente. Um programa educacional, direcionado à população em geral e principalmente para profissionais que terão contato direto com o epiléptico, contribuirá muito para uma atitude mais positiva e menos preconceituosa, com consequente melhora da qualidade de vida desses pacientes.

O objetivo de nosso estudo foi a avaliação de conhecimentos básicos sobre as epilepsias e de atitudes frente a um paciente durante crise epiléptica.

\section{CASUISTICA E METODOLOGIA}

Foi elaborado questionário (Anexo 1) de linguagem simples e fácil compreensũo por leigos, abrangendo os principais pontos básicos sobre as epilepsias. Foram submetidos a esse questionário professores de primeiro e segundo graus de escolas particulares e públicas e professores universitários de áreas médica e não médica, num total de 97 pessoas.

A escclina das escolas foi aleatória, restringindo-se a escolas da Grande São Paulo. Não foi estipulacio o número de respostas possíveis para cada questão e nem a obrigatoriedade de resposta a tcdas elas. Com base nessas informações, foram avaliados os conhecimentos desses profegsores sobre as epilepsias.

\section{RESULTADOS}

Todos os professores responderam o questionário, alguns não responderam todas as questōes e outros deram duaș ou mais respostas para uma mesma pergunta. Não observamos diferenças entre os resultados obtidos dos professores de escolas públicas e de particulares.

Do total, $94,7 \%$ consideraram que alunos com epilepsia apresentam o mesmo rendimento escolar que alunos não epilépticos.

Nenhum professor acredita na contagiosidade das epilepsias e $\mathbf{9 7 , 7 \%}$ responderam que as crises são decorrentes do aumento da excitabilidade cerebral.

Nas questōes referentes a atitudes perante aluno que estivesse apresentando convulsão, 90,8\% dos professores esperariam sua recuperação e, depois, lhe ofereceriam ajuda. Diante de uma convulsão, 50\% introduziriam objetos na boca do paciente, sendo que $39,1 \%$ dos professores de área médica tomariam a mesma atitude. Após a convulsão, 96,9\% dos professores referiram que o melhor a ser feito era deixar que a pessoa descansasse para se recuperar.

Quando questionados a respeito dos medicamentos anti-epilépticos, apenas 12,2\% responderam que eles podem levar à cura completa. Dos professores de área médica, apenas 28,5\% responderam que acreditam na cura e $87,7 \%$ consideram que esses medicamentos e.penas levam a diminuição do número de crises epilépticas.

Do total, $20,2 \%$ mencionaram o caráter hereditário das epilepsias, 31,3\% que estas são sempre secundárias a lesões cerebrais, $28,2 \%$ que significa o mesmo que «disritmia»e $20 \%$ que as epilepsias săo muito frequentes e podem aparecer em qualquer idade.

Nenhum professor de primeiro e segundo grau acredita que as epilepsias sejam mais frequentes nas classes sócio-econômicas mais baixas.

Dentre os professores de área médica, $13,6 \%$ responderam que as epilepsias geralmente são hereditárias, 4,5\% consideraram que somente aparecem nos casos em que existe lesão cerebral, 56\% afirmaram que epilcpsia significa o mesmo que «disritmia» e 31,8\% responderam que as epilepsias são muito trequentes e podem aparecer em qualquer idade.

\section{COMENTARIOS}

A falta de conhecimentos básicos sobre as epilepsias foi observada na maioria dos professores, inclusive nos de área médica. Essa falta de conhecimentos se estendeu também quanto à atitude perante uma pessoa em convulsão. Nesses casos, metade dos professores não sabe agir corretamente, inclusive os de área 
Anexo 1. Questionário.

Este questionário faz parte de estudo cujo principal objetivo é a avaliação de conhecimentos básicos relativos as epilepsias.

Sexo:

Professor(a):
( ) Escola de primeiro grau estadual
( ) Escola de primeiro grau particular
( ) Escola de segundo grau estadual
( ) Escola de segundo grau particular
( ) Universidade - área médica
( ) Universidade - área não médica

1 - As pessoas com epilepsia têm crises quando:
a) algo as assusta
b) a eletricidade de seu cérebro fica sem controle
c) tentam fazer muitas coisas ao mesmo tempo

2 - Se uma pessoa com epilepsia parece sem expressão ou perdida por alguns momentos o melhor a fazer é:

a) esperar sua recuperação e então oferecer-lhe ajuda

b) sair correndo e chamar um médico

c) dar-lhe um susto para que acorde

d) fugir, pois a pessoa pode machucá-lo

3 - Se durante uma crise a pessoa cai e se debate você deve:

a) tentar detê-la

b) afastar objetos que possam machucá-la

c) introduzir algo em sua boca para que não morda a língua ou se asfixle

d) oferecer-lhe água para beber

4 - Após a crise você deve:
a) forçar o individuo a comer
b) fazê-lo exercitar-se
c) deixá-lo descansar para que se recupere

5 - Os portadores de epilepsia:

a) têm o mesmo rendimento escolar que os não epilépticos

b) podem parar a crise se tentarem

c) geralmente apresentam tendência à loucura

6 - Os portadores de epilepsia tomam medicamentos que:
a) podem curá-los completamente
b) não ajudam muito
c) apenas diminuem freqüência de crises

7 - Como agir frente a um portador de epilepsia:
a) mostrar medo como as outras pessoas
b) fugir, pois a epilepsia é contagiosa
c) dar atenção especial
d) tratar normalmente

8 - As epilepsias:

a) geralmente são hereditárias

b) aparecem apenas nos casos em que existe lesão cerebral

c) significam o mesmo que disritmia

d) são freqüentes e aparecem em qualquer idade

e) são mais freqüentes em classes sócio-econômicas baixas 
médica. Iivanainen et al.5, em pesquisas realizadas com a população em geral, constataram que apenas $12 \%$ de seus entrevistados sabiam como agir nessa situação.

A maior parte dos entrevistados não acredita que os medicamentos antiepilépticos possam levar a cura completa, promovendo apenas a diminuição da frequência das crises epilépticas. Dos professores de área médica, apenas 28,5\% acreditam em cura, confirmando assim o insuficiente conhecimento desses profissionais em relação às diferentes evoluções das síndromes epilépticas.

A desinformação torna-se evidente quando a metade dos professores de área médica respondeu que epilepsia significa o mesmo que "disritmia" e que só aparece quando existe lesão cerē̉ral.

Dois fatos importantes têm que ser combatidos no que se refere às epilepsias: um é a desinformação da população em geral e o outro é a falta de conhecimento dos profissionais de área médica que, mesmo não sendo neurologistas, frequentemente atendem esses pacientes. Esse desconhecimento por parte dos médicos também foi observado por Beran et al.1.

A desinformação da população em geral é importante e pode afetar diretamente a vida dos pacientes epilépticos em qualquer faixa etária. Vinson 11 e Canger \& Cornaggia 2 constataram o preconceito que as crianças epilépticas enfrentam com os pais de crianças não epilépticas, que desaprovam que seus filhos estudem ou brinquem com elas.

Mac Intyre 6, Sands \& Zalking 8 e Gloag 4 relataram as dificuldades que os adultos epilépticos enfrentam para conseguir empregos. Tem sido relatado que os pacientes epilépticos têm o mesmo índice de produtividade no trabalho, menor absenteísmo e menor índice de acidentes de trabalho 6,8,9.

Mudge \& Turner 7 reportaram que a educação tem excelente resultado. Caveness \& Gallup 3 estudaram a população adulta dos Estados Unidos por 30 anos e concluiram que um maior conhecimento e esclarecimento da população foram o resultado de muitos esforços educacionais.

A educação de médicos e professores, ressaltando a importância de atitude positiva frente às epilepsias, é essencial e pode ajudar a melhorar a qualidade de vida e o tratamento médico dos pacientes com epilepsia.

\section{REFERENCIAS}

1. Beran RG, Jennings VR, Read T. Doctor's perspectives of epilepsy. Epilepsia 1981, $22: 397-406$.

2. Canger $R$, Cornaggia C. Public attitudes toward epilepsy in Italy: results of a survey and comparision with USA and West Germany data. Epilepsia 1985, 26:221-226.

3. Canveness WF, Gallup GH Jr. A survey of public attitudes toward epilepsy in 1979 with an indication of trends over the past thirty years. Epilepsia 1980, 21:509-518.

4. Gloag D. Epilepsy and employment. Br Med J 1985, 291:2-3.

5. Iivanainen M, Uutela A, Villkkumaa I. Public awareness and attitudes toward epilepsy in Finland. Epilepsia 1980, 21:413-423.

6. Mac Intyre I. Epilepsy and employment. Comm Health 1976, 7:195-204.

7. Mudge PR, Turner W. Health education on epilepsy. Aust Fam Phys 1987, 16:1356-1365.

8. Sands H, Zalking SS. Effects of an educational campaign to change employer attitudes toward hiring epileptics. Epilepsia 1972, 13:87-96.

9. Scambler G, Hopkins A. Social class, epileptic activity and disavlantage at work. J Epidemiol Comm Health 1980, 34:129-133.

10. Udel MM. The work performance of epileptics in industry. Arch Environm Health 1960, 257-264.

11. Vinson T. Towards demythologizing epilepsy. Med J Aust 1975, 2:663-663. 